\title{
MSFD Descriptor 9: Between Health and Environment
}

\author{
C. Maggi, S. Lomiri, M. T. Berducci, B. Di Lorenzo, M. D’Antona, and A. Ausili
}

\begin{abstract}
The aim of the Marine Strategy is to achieve or maintain good environmental status (GES) in marine waters across Europe, by means a set of 11 descriptors, and to ensure that the marine use is compatible with the conservation of ecosystems. Italy performed the initial assessment (IA), according to Descriptor 9, of the marine waters under its jurisdiction; to do that, Italy proposed statistical range of acceptance to achieve the GES, identified a method to use health results for assessing environmental status.

Some reflections and considerations that emerged during IA phase, performed under D9, are reported in order to help to clarify and simplify some technical aspects, particularly with respect to terms and concepts unclear that, if ignored, could cause a not correct evaluation.
\end{abstract}

Index Terms-Descriptor 9, good environmental status, MSFD, public health, seafood.

\section{INTRODUCTION}

In order to protect and restore ecological quality or integrity, within estuarine, coastal and offshore systems, Europe has moved towards coordinated and integrated catchment-to-coast management, following the most novel legislation on ecosystem-based approaches [1]. Human impacts on marine ecosystems [2]-[4] such as land-based industrial activity, urban discharge, pesticide use, nuclear accidents and discharges, aquaculture, heavy shipping lines might be responsible for elevated levels of contaminants in sediment and biota, including species for human consumption.

The most recent marine European legislation is Framework Directive 2008/56/EC (MSFD, [5]) on the Strategy for the Marine Environment, subsequently implemented in Italy with the Legislative Decree n. 190 of 13 October 2010 [6]. The MSFD requires that Member States take measures to achieve or maintain Good Environmental Status (GES) by 2020. MSFD Annex I includes a set of 11 descriptors, on the basis of which GES should be determined (Table I).

Some descriptors deal with general status of the environment, others with specific habitat integrity or specific pressures.

The Commission Decision of 1 September 2010 ([7] COM DEC 2010/477/EU) listed 29 criteria and 56 indicators, including a factors' combination in relation to state, impacts and pressures, to assess GES for each descriptor of the MSFD Annex I. Each Member State

Manuscript received October 22, 2014; revised March 13, 2015

The authors are with ISPRA, Institute for Environmental Protection and Research, Rome, Italy (e-mail: chiara.maggi@isprambiente.it, serena.lomiri@isprambiente.it,_mariateresa.berducci@isprambiente.it, bianca.dilorenzo@isprambiente.it, marco.dantona@isprambiente.it, antonella.ausili@isprambiente.it). provided the Initial Assessment (IA) of own marine waters, together with the definition of targets and monitoring indicators (MSFD art. 8, [5]), taking account of existing data, where available, specifying the essential features and characteristics and current environmental status of the waters. So, Italy sent to the European Commission in April 2013 the IA of marine waters under its jurisdiction.

\begin{tabular}{cl} 
TABLE I: DESCRIPTORS OF GES (ANNEX I COM DEC 201074777EU) \\
\hline \hline No. & Descriptor \\
\hline 1 & Biological diversity maintained \\
\hline 2 & Non-indigenous species \\
\hline 3 & Commercial fish \& shellfish \\
\hline 4 & Food-webs \\
\hline 5 & Eutrophication \\
\hline 6 & Sea-floor integrity \\
\hline 7 & Hydrography \\
\hline 8 & Contaminants \\
\hline 9 & Contaminants in seafood \\
\hline 10 & Litter \\
\hline 11 & Energy, incl. underwater noise \\
\hline \hline
\end{tabular}

The 11 descriptors are very diverse, although closely linked to each other, covering all aspects of marine environmental conservation and protection [8]. Among pressure descriptors, Descriptor 8 and Descriptor 9 are dealing with contaminants, but have distinct and different objectives: protection of the environment the first one, protection of the human health the second one. Anyway, also Descriptor 9, which is an health descriptor, has to contribute to the assessment of the environmental status. So, it becomes necessary to identify possible relations between contaminant levels in seafood tissues and the status of marine environment. In particular, it should be understood the role of Descriptor 9 beyond the Food Safety Legislation and how to use health data to assess marine environment, as monitoring programs designed for public health objective focus on estimating consumer exposure rather than assessing environmental status. This paper reports the main findings arising from the IA of the marine waters under the Italian jurisdiction, so as shortcomings linked to use health results. Some reflections and remarks, which emerged during this assessment phase performed under D9, are reported too.

\section{DESCRIPTOR 9}

Descriptor 9 defines the need to monitor contaminants, as established in the Commission Decision [7], "in edible tissue of fish, crustacean, molluscs and echinoderms, wild 
caught", and requires that "levels do not exceed European, regional or national levels for products destined to human consumption". The evaluation is carried out by the use of two indicators taking into account i) the actual levels that have been detected and the number of contaminants for which exceeding levels have been detected, ii) the frequency of exceeding the regulatory levels.

Descriptor 9 necessarily implicates a balance between health information and environmental assessment. The presence of contaminants, in fish and other seafood, above the health regulatory levels might have a negative influence both on the health of the consumer and on the sustainable use of marine resources, and consequently on the environment [9]. According to Decision 2010/477/EU [7], Good Environmental Status should be achieved when contaminants are below the levels fixed for human consumption; the absence of human health hazards may however involve environmental pollution effects, since these could be present at lower contaminants concentration.

\section{A. Italian Experience}

European marine waters divided in 4 regions by Marine Strategy Directive: Baltic, North East Atlantic Ocean, Mediterranean Sea and Black Sea. Some of them, as Mediterranean Sea, had been subdivided in subregions. Commission Decision of 1 September 2010 [7] established that Member States have to do initial assessment in each subregions of own jurisdiction. So, the IA of Italian waters performed in Western Mediterranean Sea (WMS), Adriatic Sea (AS) and Ionian Sea and the Central Mediterranean Sea (ISCMS) subregions.

During the IA phase, all substances for which maximum regulatory levels have been laid down for public health reasons in fish, shellfish and other marine products destined for human consumption were examined; moreover number and frequency of contaminants exceeding maximum regulatory levels were calculated [10]. Anyway, existing health monitoring data were not enough to assess Italian marine water under Descriptor 9, so Italy used also results coming from environmental monitoring in order to fill data gaps.

To evaluate compliance to GES under Descriptor 9, statistical ranges of acceptance, based on the thresholds identified in the relevant national and international laws, were calculated for the concentrations of regulated contaminants (Reg. 1881/2006 and further updates [11]).

Data referred mainly to coastal zones and were related to areas where fishing activities take place. Information useful for assessment under Descriptor 9 concerned edible portion of different target species, such as coastal fish, tuna, mullets, mussels, sharks, crustaceans, cephalopods. Species were selected for their commercial and environmental importance, following recommendations reported in Annex II of Task Group 9 Report [9], but also to represent their spatial coverage of the entire subregion as better as possible. Italy didn't considered farmed fish, as recommended by Task group 9, but only farmed mussels, since there isn't contamination through feed.

The Italian IA has been performed on the basis of more than 15000 data coming from only national water, relating to chemical substances as heavy metals (lead, cadmium, and mercury), polycyclic aromatic hydrocarbons (benzo(a)pyrene, benzo(a)anthracene, benzo(b)fluoranthene and chrysene) and dioxins (including dioxin-like PCBs). Data were georeferenced in GIS and different integration levels were performed (for station, for cell grid, for year). At last data were elaborated and those unfitting in analytical quality (Annex III of Commission Regulation (EC) No $882 / 2004$ [12]), in MSFD criteria and in GIS elaborations standards, were removed.

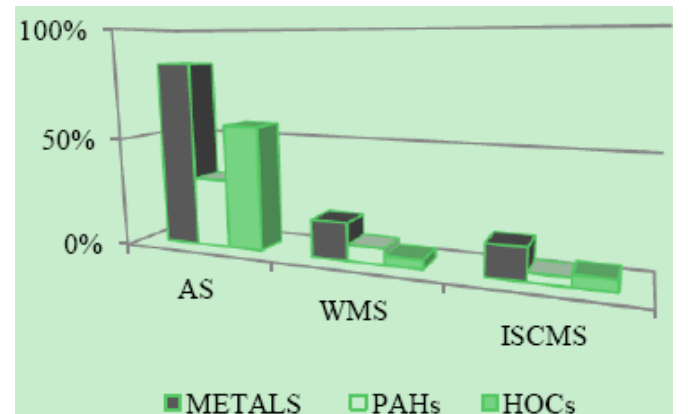

Fig. 1 Data spatial coverage for chemical compounds in Italian subregions.

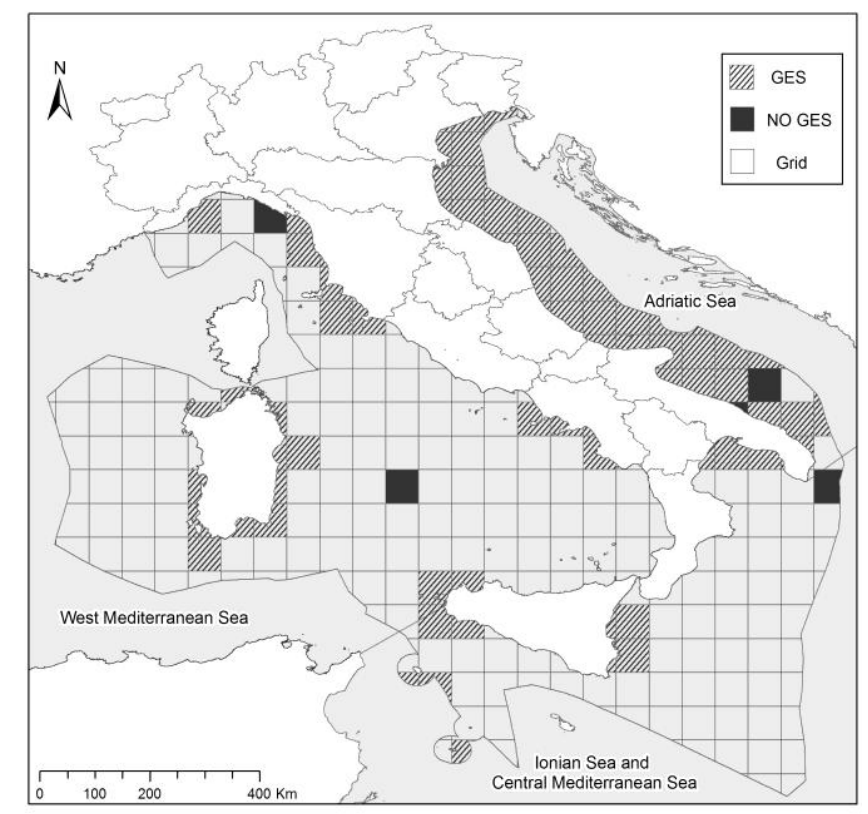

Fig. 2. Environmental quality status of Italian marine water relating to Mercury by means foodstuff.

Analyzing the collected information, it was possible to observe that the most part of data concerned Metals, proving that inorganic elements are usually more investigated than organic (Fig. 1). Subregion with the greater data coverage was the Adriatic one, where spatial coverage was more than $80 \%$ for Metals, more than $50 \%$ for PCBs and near to $30 \%$ for PAHs, probably because the most part of mussels farming plants are located in Adriatic Sea subregion. In fact, data percentages showed that the favourite organisms to assess the health risk are generally bivalve molluscs, owning all characteristics of a bioindicator organisms, as recognized by the international scientific [13].

In the Ionian (ISCMS) subregion, data spatial coverage had a lower extent, especially concerning to PAHs and dioxin-like compounds. A possible cause of not enough monitoring performed for dioxin and dioxin-like compounds could be the complexity of analytical procedure [14]. 
Fig. 2 shows the environmental quality status of Italian subregions, with reference to mercury in fishery products. Outcomes are extracted from Maggi et al., 2014 [10].

Despite some exceedances, environmental quality of Italian subregions is good overall, regarding Metals, PAHs, Dioxins and Dioxin like compounds, taking into account coverage percentages too. Indeed, concentrations over thresholds are linked not only to the presence of the pollutant, but rather to a whole range of biological (species, age growth degree) and environmental (temperature, geochemical anomalies, salinity) factors [15], [16]. Human health programs effectively not contemplate seasonal variation, age and sex which influence contaminants' bioavailability in fish and seafood. So higher levels of contaminants concentrations should not automatically be interpreted as a negative status [10].

\section{BETWEEN HEALTH AND ENVIRONMENT: ITALIAN REMARKS}

During the IA of Italian marine water quality, a number of gaps and weak points concerning Descriptor 9 have emerged, particularly with respect to terms and concepts unclear that could left space to individual or mistaken interpretations. On the other hand a revision of Commission Decision 2010/477/EU [7], to clarify and simplify some technical aspects, would be desirable, as recommended by $\S(4)$ of Decision itself "as soon as possible after the completion of the initial assessment."

\section{A. Chemical Substances}

MSFD D9 requests to each Member State to monitor concentrations of substances, for which regulatory levels are established for products destined to human consumption, and number of contaminants which have exceeded maximum regulatory levels.

Chemical contaminants, potentially present in seafood, can be of different nature and toxicity and are often present concurrently at different levels of concentrations in various species. Moreover, there are other substances, typical of a specific area, activity or input source, that should be important to monitor. Between them, there are substances for which legislation doesn't envisage a threshold but that are relevant for an hypothetic risk, concerning both health and environmental protection.

For instance, other metals, beyond those regulated, might become toxic when elevated doses are ingested [17], [18]. Furthermore, it would be opportune to set a limit also for total PAHs, organochlorine pesticides and organotin compounds.

Nevertheless, also existing regulatory levels are not properly usable for environmental purpose. Besides, Task Group 9 already warned that, in order to assess environmental status, the use of thresholds set for public health protection wouldn't be correct, because they are generally too high to be used as an indicator for the pollution of the marine environment [9]. Conversely, it would be helpful to clarify whether the Environmental Quality Standards, fixed by Directive 2013/39/EU [19], can be used to D9 purpose. This new Directive added (for 8 new substances) EQSs in biota matrix, for environmental purpose, although the basis of EQSs derivation has been the protection of human health and these established environmental levels are too low to assess human health.

About number of contaminants, European Community does not provide any indication concerning the relevance of the number of contaminants exceeding threshold levels, nor provides a maximum number of excesses which affects compliance to GES. Because of this lack of information, it is noticeable that the contribution given by the record of the number of contaminants is irrelevant. So, because of what, Italy during the initial assessment phase didn't take into consideration the number of contaminants that exceeded regulatory levels, considering this information not useful for assessing the quality of marine waters under D9.

\section{B. Sampling Strategy}

In order to assess in a proper way the status of national waters, Italy used, for IA purpose, both results from health and environmental monitoring. In this way it has been possible to reach a greater coverage of information needs for evaluating compliance to GES under Descriptor 9. Existing monitoring programmes intended to assess marine environmental quality and human health safety usually apply different approaches and methodologies. While environmental monitoring programs measure contaminants in the marine environment in a wide range of matrices and using a wide variety of techniques, health monitoring programs only measure levels of contaminants in fish and other seafood using analytical techniques determining those trace elements or compounds for which regulatory limits have been set. Moreover size, age, sex and season data, useful in environmental data analysis, often are not recorded, overlooking phenomena as bioaccumulation, for that contamination changes according to the trophic level considered, with estimates higher in larger species, i.e. pelagic fish, containing more fat and occupying an higher food web position [14]. So, the exceedances of regulatory levels cannot be defined certainly as an index of marine environmental contamination. For these reasons, the knowledge of biological factors (species, trophic level, diet, condition, size, age) and the traceability of the samples are essential in determining compliance with regulatory standards. In addition, human health programs focus on edible parts of the fish (mainly muscle), as recommended also in legislation, while in environmental monitoring programs the sampling is carried out in different matrices.

About size, Descriptor 9 ground on fish market products, including all sizes of foodstuff sold for human consumption rather than focusing on a standardized sample, that offers greater possibilities in comparing degrees of contamination in the marine environment. Anyway, some samples collected for environmental purpose could be processed for GES evaluation under D9, when the species are market size and the edible tissues are analyzed.

About the traceability, it is important to consider that seafood is widely transported and its provenance may not be identifiable, so human exposure monitoring programs often lack the necessary data to link the samples to specific (sub) regions. A focal point concerning traceability is the processing chain that can tangle the identification of geographical origin of the sample: for environmental 
assessing purpose, it is important to be able to link a species collected to a retail to the real catching area.

The selection of species chosen for environmental monitoring is not less important. Bioindicator specie used for environmental monitoring must meet certain requirements such as accumulating high levels of pollutants without death, high abundance and wide distribution, low dispersion ability or sessile lifestyle, representing local pollution [20]. Biological factors (as trophic level, diet, spawning cicle,..) of selected species must be well known by researchers who carry on data analysis. It would be fair to investigate one species per each trophic level (shellfish, fat fish,...), although certain commercial fish species are highly migratory and cannot be used to assess the GES of a particular marine area.

To face these points, Italy took care to make a selection of species, choosing those more prone to biomagnify/bioaccumulate regulatory classes of contaminants, species representative of the different trophic levels or habitats, species representative for different subregions. Moreover, the sampling area were selected considering particular features of each subregion, i.e. areas rich in mercury by nature or more prone to maritime traffic, then prone to hydrocarbons pollution. In Table II focal points on existing monitoring programs are summarized.

\section{Evaluation Approach}

Activities connected to Marine Strategy should take in consideration the measurement and assessment of relevant contaminants considered in other directives, first of all Water Framework Directive (2000/60/CE) [21]. If the WFD is the first law instrument that considers both physical, chemical and biological environmental aspects, MSFD proposes an ecosystem approach higher that reaches the human health topic with Descriptor 9. Surely between the two Directives there is a connection concerning the approaches for environmental assessing, but it being understood that there are also substantial differences, for example the incoherence between values proposed or areas included in protection activities. Threshold values included in WFD, as mentioned above, are too low for D9 purpose; extension of regulated areas are limited to national waters for WFD, while the MSFD assessment concern also open sea [22].

Since Directive 56/2008/EC [5] does not give specific rules, allowing Member States to adopt different criteria in order to use correctly health data for assessing environmental quality, Italy chose not consider the "one out, all out" (OOAO) approach (used by the WFD Directive (2000/60/CE), that assess the environmental status on the basis of the worst element. This choice was made to avoid to assess in bad status a subregion where just a contaminant exceed regulatory levels for Descriptor 9. Otherwise this judgment could easily be interpreted that consumption of all fish and seafood originating in that (sub) region would be dangerous. GES definition under D9 is too focused only on threshold value exceeding, should instead take into account the overall content of the various categories of pollutants even in the absence of the excess.

So, different integration levels were performed by Italy: data within the same station; several stations falling in the same grid cell; same grid cell in different years. In this way the subregion's status was judged by means a spatial integrated response, preventing to assess the outcome of a single sample, as instead requested by human consumption legislations and by OOAO principle [10]. In order to avoid losing information, a statistical range of acceptance was introduced.

\section{RESUlT}

During Initial Assessment, shortcomings linked to use health results were highlighted and these gaps could be filled through new monitoring programs, which will be directed towards a correct assessment strategy.

Surely new data must be collected, in order to complete the spatial coverage of each contaminant category, for each subregion. This will possible designing new monitoring programs, in addition to existing monitoring programs concerning human health, that take in account the particularities of environmental assessment under Descriptor 9.

Focal point on which pay particular attention will be the choice of target species, with bioindicator features, as well as the record of the origin area and biometric data for each specimen collected. These new monitoring programs under D9 should be prone to collect data for open sea too.

TABLE II: FOCAL POINTS ON EXISTING MONITORING PROGRAMS

\begin{tabular}{lcc}
\hline \hline Features & Health & Environment \\
\hline Regard only edible species & yes & no \\
Follow reference threshold values & yes & yes \\
Use criteria as EQS, EAC and/or SQG* & no & yes \\
$\begin{array}{l}\text { Use thresholds values set for the protection of } \\
\text { human health }\end{array}$ & yes & yes \\
$\begin{array}{l}\text { Use thresholds values set for environmental } \\
\text { assessment }\end{array}$ & no & yes \\
$\begin{array}{l}\text { Assure traceability for each specimen sampled } \\
\text { Collect entry of different size, age and sex }\end{array}$ & no & yes \\
$\begin{array}{l}\text { Provide for standardised sampling } \\
\text { Involve processed seafood (i.e. smoked meat) }\end{array}$ & yes & yes \\
$\begin{array}{l}\text { Consider aquaculture products } \\
\begin{array}{l}\text { Take note of biological factors of species } \\
\text { collected }\end{array}\end{array}$ & yes & no \\
\hline \hline $\begin{array}{l}\text { EQS: Environmental Quality Standards; } \\
\text { Assessment Criteria; SQG: Standard Quality Guidelines) }\end{array}$ & Environmental \\
\hline
\end{tabular}

\section{CONClUSION}

During Initial Assessment, shortcomings linked to use health results were highlighted and these gaps could be filled through new monitoring programs, which will be directed towards a correct assessment strategy.

Surely new data must be collected, in order to complete the spatial coverage of each contaminant category, for each subregion. This will possible designing new monitoring programs, in addition to existing monitoring programs concerning human health, that take in account the particularities of environmental assessment under Descriptor 9.

Focal point on which pay particular attention will be the 
choice of target species, with bioindicator features, as well as the record of the origin area and biometric data for each specimen collected. These new monitoring programs under D9 should be prone to collect data for open sea too.

Furthermore they should include several contaminants, also those not considered in health legislation but useful in order to assess environmental quality. In addition, sampling cruises should be carry out with a temporal frequency that allows to study the behaviour of not-regulated contaminants and to evaluate temporal trend of reduction of concentration.

Surely, another aspect to improve is the flow of information coming from institutions working in the health field, in order to validate the applied methodology and help to extend the use of health information arising from chemical contamination of seafood for the evaluation of the quality of the marine environment.

\section{REFERENCES}

[1] A. Borja, M. Elliott, J. Carstensen, A. Heiskanen, and W. van de Bund, "Marine management - Towards an integrated implementation of the European Marine Strategy Framework and the Water Framework Directives," Mar. Pollut. Bull., vol. 60, pp. 2175 2186, 2010.

[2] N. Ban and J. Alder, "How wild is the ocean? Assessing the intensity of anthropogenic marine activities in British Columbia, Canada," Aquatic. Conserv.: Mar. Freshw. Ecosyst., vol. 18, pp. 55-85, 2008.

[3] B. S. Halpern, S. Walbridge, K. A. Selkoe, C. V. Kappel, and F. Micheli, "A global map of human impact on marine ecosystems," Science, vol. 319, pp. 948-952, 2008.

[4] A. Borja, M. Elliott, J. H. Andersen, A. C. Cardoso, and J. Carstensen, "Good Environmental Status of marine ecosystems: What is it and how do we know when we have attained it?" Mar. Pollut. Bull., vol. 76, no. 1-2, pp. 16-27, 2013.

[5] Framework Directive 2008/56/EC (MSFD) on the Strategy for the Marine Environment, 2008

[6] Legislative Decree No. 190, October 13, 2010.

[7] Commission Decision 2010/477/EU, September 1, 2010

[8] J. Gago, L. Vinas, V. Besada, and J. Bellas, "The link between descriptor 8 and 9 of the marne strategy framework directive: Lessons learnt in Spain," Environ. Sci. Pollut. Res., vol. 21, no. 23, pp. 13664 13671, Dec 2014.

[9] F. Swartenbroux, B. Albajedo et al. Marine Strategy Framework Directive - Task Group 9 Report Contaminants in fish and other seafood. EUR 24339 EN-2010. [Online]. Available: http://publications.jrc.ec.europa.eu/repository/handle/111111111/136 69

[10] C. Maggi, S. Lomiri, B. D. Lorenzo, M. D’Antona, and M. T. Berducci, "Environmental quality of Italian marine water by means of marine strategy framework directive (MSFD) descriptor 9," PLOS ONE, vol. 9, no. 9, 2014.

[11] Commission Regulation (EU) No 1881/2006, December 19, 2006.

[12] Commission Regulation (EU) No 882/2004, April 29, 2004.

[13] F. Galgani, C. Martínez-Gómez, F. Giovanardi et al., "Assessment of polycyclic aromatic hydrocarbon concentrations in mussels (Mytilus galloprovincialis) from the Western basin of the Mediterranean Sea,' Environ. Monit. Assess., vol. 172, no. 1-4, pp. 301-317, 2010.

[14] R. Miniero, E. De Felip, M. Magliulo, F. Ferri, and A. Di Domenico, "Selected persistent organic pollutants (POPs) in the Italian environment," Ann. Ist. Super. Sanita., vol. 41, no. 4, pp. 487-492, 2005.

[15] D. Jureša and M, Blanuša, "Mercury, arsenic, lead and cadmium in fish and shellfish from the Adritic Sea," Food Addit. Contam., vol. 20, no. 3, pp. 241-246, 2003.

[16] A. A. Pastorelli, M. Baldini, P. Stacchini et al., "Human exposure to lead, cadmium and mercury through fish and seafood product consumption in Italy: a pilot evaluation," Food Addit. Contam. Part A, vol. 29, no. 12, pp. 1913-1921, 2012.

[17] C. A. Menzie, L. M. Ziccardi, Y. M. Lowney et al., "Importance of considering the framework principles in risk assessment for metals," Environ. Sci. Technol., vol. 43, pp. 8478-8482, 2009.

[18] G. O. Conti, C. Copat, C. Ledda, M. Fiore, R. Fallico, S. Sciacca, and M. Ferrante, "Evaluation of heavy metals and polycyclic aromatic hydrocarbons (PAHs) in Mullus barbatus from sicily channel and risk-based consumption limits," Bull. Environ. Contam. Toxicol., vol. 88, pp. 946-950, 2012.

[19] Directive 2013/39/EU, 2013

[20] L. Vinas, V. Besada, and J. L. Sericano, "Sampling of fish, benthic species, and seabirds eggs in pollution assessment," in Comprehensive Sampling and Sample Preparation, J. Pawliszyn and J. M. Bayona, Eds. Elsevier, Academic Press: Oxford, UK, pp. 349-372, 2012.

[21] Water Framework Directive (WFD) 2000/60/EC, 2000.

[22] HM Government. (2012). Links between the marine strategy framework and water framework directives. [Online]. Available: http://archive.defra.gov.uk/environment/marine/documents/legislation /msfd-factsheet1-waterdirective.pdf

C. Maggi was born in Rome on December 25, 1968 and received the chemistry master degree from Sapienza, University of Rome, in 1994. Maggi earned a PhD degree in Industrial Chemical Processes in 2004. She collaborated to research activity in analytical chemistry and industrial applied chemistry in "La Sapienza" University of Rome. Since July 2000 she has been working as a researcher in ISPRA, National Institute for Environmental Protection and Research (ex-ICRAM, Central Institute for Marine Research). She has gained a wide experience in assessment of environmental quality of marine coastal areas; development and standardization of chemical analytical methods; validation of analytical methods, quality assurance and quality control; assessment of the toxicological effects of contaminants on marine organisms; definition of guidelines and criteria for the preparation of plans for monitoring the activities of handling of the seabed (offshore structures, cables and pipelines, nourishments). She has been carrying out scientific and technical support to the Ministry of Environment to the preparation of the proof of several ministerial decrees about definition of environmental quality standard (EQS) for aquatic ecosystems and technical specifications of chemical analysis and monitoring of water bodies. Since 2000 she has been responsible of laboratory activities of Environmental Inorganic Chemistry and since 2009 she is the coordinator of ISPRA Task Group for Initial Assessment Activity of Marine Strategy Framework Directive (2008/56/EC) relating to Descriptor 8 "Concentrations of Contaminants Are at Levels not Giving Rise to Pollution Effects" and Descriptor 9 "Contaminants in Fish and Other Seafood for Human Consumption Do not Exceed Levels Established by Community Legislation or Other Relevant Standards".

S. Lomiri was born in Rome on August 19, 1979 and received the biology degree from "La Sapienza", University of Rome in April 2006. After a degree in achievement, she began her research activity in National Institute for Environmental Protection and Research working on macrozoobenthic communities, in particular on polychaeta taxon. She develops experience in environmental characterization of marine areas, in assessing environmental status, in particular by means of biotic matrix, in monitoring environmental effects of pipelines and offshore structures. Since 2012 she is a collaborator of ISPRA Task Group for Initial Assessment Activity of Marine Strategy Framework Directive (2008/56/EC) relating to Descriptor 1 "Biological Diversity Maintained", Descriptor 8 "Concentrations of Contaminants Are at Levels not Giving Rise to Pollution Effects" and Descriptor 9 "Contaminants in Fish and Other Seafood for Human Consumption Do not Exceed Levels Established by Community Legislation or Other Relevant Standards".

M. T. Berducci was born in Rome on March 22, 1980 and received the chemistry degree from Sapienza, University of Rome, in 2005. After the completion of master chemistry degree in analytical methodologies at the same university in 2007, Berducci began to collaborate with Central Institute for Marine Research. Now she is a researcher by ISPRA National Institute for Environmental Protection and Research and her research's activity interests development of methods for determination of heavy metals in marine organism and sediments, environmental characterization of marine areas and monitoring of heavy metals in biotic and abiotic matrices in coastal and marine environmental. Since 2012 she is a collaborator of ISPRA Task Group for Initial Assessment Activity of Marine Strategy Framework Directive (2008/56/EC) relating to Descriptor 8 "Concentrations of Contaminants Are at Levels not Giving Rise to Pollution Effects" and Descriptor 9 "Contaminants in Fish and Other Seafood for Human Consumption Do not Exceed Levels Established by Community Legislation or other Relevant Standards".

B. Di Lorenzo was born in Rome on May 15, 1980. In 2004 she received the statistics degree from La Sapienza University of Rome and in 2011 the 
PhD degree in statistical methodology from the Department of Statistical Sciences. From 2005 she began to collaborate with Central Institute for Marine Research. Now she is a researcher by ISPRA and her research interest is on time series analysis and long memory processes and works on elaboration of environmental data, for the characterization of marine areas and monitoring of contamination on biotic and abiotic matrices.

M. d'Antona was born in Rome on March 25, 1976 and received the natural science degree from "La Sapienza" University in Rome, in 2004. In 2006, after the completion of master environmental scienze degree in defense and maintenance of the territory, he began the $\mathrm{PhD}$ school in earth science at "La Sapienza" University in Rome, on applied geochemistry and isotope techniques. Now he is a researcher in ISPRA and he works on data management, GIS data processing and spatial data analysis.

A. Ausili was born in Rome on December 26, 1960 and received the chemistry master degree from La Sapienza, University of Rome, in 1986. She had worked from 1986 to 1990 by the Department of Applied Toxicology of National Institute of Health and since 1991 she has been a senior researcher in National Institute for Environmental Protection and Research, Central Institute for Marine Research Central, Department of Anthropogenic Impact in marine environment. Her previous research interest assessment of contamination is in marine organisms and sediments by polycyclic aromatic hydrocarbons, organochlorine compounds and organophosphorus compounds, through the development of appropriate analytical methodologies; characterization physical-chemical and ecotoxicological of the dredging sediment in order to study the possible effects on marine organisms; assessment of the toxicological effects of contaminants on marine organisms; assessment of the environmental quality of coastal areas. Since 1991 she has been responsible of the laboratory activities of Organic Contaminats and has been taking part in many ISPRA research projects. She has been carrying out scientific and technical support to the Ministry of Environment for the Departments: Sea Defence, Protection of Continental Waters, Wastes and Reclamations on marine environmental impact due to man induced activities. Since 2006 she has been taking part, as a expert nominated by Environmental Ministry, in European Working Group for Common Implementation Strategy of Directive 2000/60/EC 